\title{
Investment Analysts' Forecasts of Earnings
}

\author{
Rocco Ciciretti, Gerald P. Dwyer, and Iftekhar Hasan
}

\begin{abstract}
The literature on investment analysts' forecasts of firms' earnings and their forecast errors is enormous. This paper summarizes the evidence on the distribution of analysts' forecasts and forecast errors using data for all U.S. firms from 1990 to 2004. The evidence indicates substantial asymmetry of earnings, earning forecasts, and forecast errors. There is strong support for average and median earning forecasts being higher than actual earnings a year before the earnings announcement. Such differences between earnings and forecasts also exist across time periods and industries. A month before the earnings announcement, the mean and median differences are small. (JEL G17, C53)
\end{abstract}

Federal Reserve Bank of St. Louis Review, September/October 2009, 91(5, Part 2), pp. 545-67.

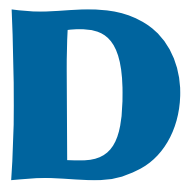

o stock analysts provide information on stocks, or are they merely salespeople issuing one-sided information about stocks? In addition to forecasting earnings that are used by some investors when they buy various firms' stocks, analysts at investment banks often have participated in other activities such as convincing the same firms to hire the investment bank to issue stock. These activities were the basis of suits by the New York attorney general against major investment banks. Rather than proceeding to trial, the charges were settled in April 2003. In the settlement, investment banks agreed to substantial changes in their business practices designed to provide less incentive for analysts to be influenced by the investment banks' other activities. The investment banks also agreed to make payments totaling $\$ 1.4$ billion, which covered fines, payments to investors, funding of investor education, and funding of research by independent analysts. This settlement brings into question the informativeness of analysts' projections of earnings, suggesting that analysts' projections of earnings largely or substantially reflect analysts' interests rather than an assessment of a firm's prospects.

On the other hand, charges of an insidertrading scheme in 2007 suggest that analysts' forecasts do contain information and affect prices. This scheme involved an accomplice receiving advance information about analysts' forecasts and taking positions before the announcements (Smith, Scannell, and Davies, 2007). This scheme makes no sense if analysts' forecasts are uninformative and ignored. While indicating that at least some analysts' forecasts may be informative, such activities do not imply that forecasts cannot be improved. It is possible to take imperfect information and filter out predictable misinformation.

Rocco Ciciretti is an assistant professor of economic policy in the SEFeMEQ department at the University of Rome at Tor Vergata. Gerald P. Dwyer is the director of the Center for Financial Innovation and Stability at the Federal Reserve Bank of Atlanta and an adjunct professor at the University of Carlos III, Madrid. Iftekhar Hasan is the Cary L. Wellington Professor of Finance at Rensselaer Polytechnic Institute and a research associate at the Berkley Center for Entrepreneurial Studies of the Stern School of Business at New York University. The Berkley Center helped make these data available to the authors. Data from the Center for Research in Security Prices (CRSP), Booth School of Business, The University of Chicago (2006), are used with permission. (All rights reserved. www.crsp.chicagobooth.edu). Much of this paper was completed while Rocco Ciciretti was a visiting scholar at the Federal Reserve Bank of Atlanta, which provided research support. Gerald Dwyer thanks the Spanish Ministry of Education and Culture for funding under project No. SEJ2007-67448/ECON. Budina Naydenova and Julie Stephens provided excellent research assistance. The authors also thank seminar participants in the XVI Tor Vergata Conference on Money, Banking, and Finance, a DECE Seminar at the University of Cagliari, and a seminar at the Bank of Italy for helpful comments. Mark Fisher, Paula Tkac, and two referees made helpful comments on earlier drafts.

(C) 2009, The Federal Reserve Bank of St. Louis. The views expressed in this article are those of the author(s) and do not necessarily reflect the views of the Federal Reserve System, the Board of Governors, or the regional Federal Reserve Banks. Articles may be reprinted, reproduced, published, distributed, displayed, and transmitted in their entirety if copyright notice, author name(s), and full citation are included. Abstracts, synopses, and other derivative works may be made only with prior written permission of the Federal Reserve Bank of St. Louis. 
Are there predictable differences between analysts' earnings forecasts and actual earnings? Many papers show that the analysts' forecast errors are predictably different from actual earnings. ${ }^{1}$ The evidence indicates that analysts' forecasts of earnings well before the announcement are higher on average than actual earnings. Whatever earnings an analyst forecasts for a firm, a better prediction is a somewhat lower level of earnings. This predictable difference is called a "bias" in the forecasts. ${ }^{2}$ Some papers also suggest that analysts' forecasts close to the earnings announcement decline to less than the actual earnings. The rationale for this reverse bias is a suggestion that earnings greater than recent forecasts are interpreted as a positive earnings surprise and the firm's stock price increases.

This paper provides an overview of analysts' forecasts and the forecasts' relationship to actual earnings. Our data are for U.S. analysts' forecasts of U.S. firms' earnings from 1990 through 2004. These data show the usual result that analysts' forecasts are greater than earnings on average. We look at the distribution in more detail and find that the distribution of earnings is asymmetric. The distribution of earnings forecasts also is asymmetric but not sufficiently asymmetric that forecast errors are symmetric; earnings forecast errors also are asymmetric. We also find that median forecasts are closer to actual forecasts than are mean forecasts. We examine differences between actual earnings and earnings forecasts over time and by industry. We find substantial differences in forecast accuracy across industries and larger forecast errors during recessions. Forecast errors at the 1month horizon are small in magnitude.

\section{ERRORS IN FORECASTING EARNINGS PER SHARE}

\section{Data}

Analysts forecast companies' earnings per share, and the forecast error is the difference

1 Sirri (2004) summarizes a few of these papers and provides references.

2 Not all research agrees that analysts' forecasts are biased-for example, Keane and Runkle (1990, 1998). between actual earnings and these forecasts of earnings. There is a scale problem with using the level of forecasts across firms and over time. A firm with the same total earnings as another but half as many shares outstanding will have earnings per share that are twice as large. One way to adjust for differences in the magnitude of earnings per share and forecast errors across firms is to divide the forecast error by the stock price. Dividing by the stock price assumes that errors in forecasting earnings per share relative to the stock price are relatively homogeneous across firms. Earnings per share relative to the stock price is the inverse of the price-to-earnings ratio, often used as part of the information used to evaluate companies. $^{3}$

The forecast error relative to the stock price is indicated as follows:

$$
e_{T, t}^{i, j}=\frac{a_{T}^{i}-f_{T, t}^{i, j}}{p_{T-1}^{i}}
$$

where $e_{T, t}^{i, j}$ is the computed relative forecast error for company $i$ by analyst $j$ for year $T$ made $t$ months before the release date, $a_{T}^{i}$ is actual earnings per share of company $i$ in year $T, f_{T, t}^{i, j}$ is the forecasted earnings per share for company $i$ by analyst $j$ made for year $T$ with the forecast being made $t$ months before the release date, and $p_{T-1}^{i}$ is the stock price for company $i$ at the end of the previous year, $T-1$.

The forecast horizon, $t$, is calculated as the difference in months between the estimation date (I/B/E/S [Institutional Brokers' Estimate System] variable ESTDATX) and the report date (I/B/E/S variable REPDATX). We use the report date instead of forecast period end date (FPEDATX) because analysts can make forecasts between the fiscal year's end and the date earnings are reported.

The data on forecasts of earnings per share and actual earnings per share are from the I/B/E/S

\footnotetext{
3 Another way to scale earnings per share is to divide by the level of earnings to get the proportional error in forecasting earnings. Earnings close to zero and negative earnings create serious problems for this normalization. Dividing by earnings can generate a very large relative forecast error as earnings go to zero; dividing by negative earnings would change the sign of the forecast error. Stock prices cannot be negative and are strictly positive in our data. Although prices can approach zero, earnings generally approach zero at a related rate, which is another way of saying that earnings per share relative to the stock price are relatively homogeneous across firms.
} 
Detail History (with Actuals) database for 1990 through 2004. Any company with at least one forecast between 1990 and 2004 is included in the initial database.

The stock prices are from the Center for Research in Security Prices (CRSP) database from 1989 to 2003. The earnings in any year are divided by the stock price at the end of trading in the prior year. With this choice of stock price, the stock price does not reflect the changes in forecasts or the ensuing forecast errors made during the year.

The initial number of observations on forecasts is $1,835,642$. To avoid nonsynchronized timing of forecasts by year, we restrict the analysis to companies with fiscal years ending in December. ${ }^{4}$ This reduces the number of observations to $1,207,445$. We further restrict our analysis to forecasts by analysts located within the United States, which reduces the number of observations to 678,427 forecasts for 6,731 companies. In this paper, a company's stock is defined by the six-digit Committee on Uniform Securities Identification Procedures (CUSIP) number followed by an “01”; this indicates a common stock. We match U.S. companies from I/B/E/S and CRSP databases by CUSIP. We also associate an industry code according to the Global Industries Classification Standard from Standard \& Poor's.

Finally, to eliminate possible transcription errors, we cut off the distributions of both actual and forecasted earnings per share relative to the stock price at the 1st and 99th percentiles for each year and forecast horizon. ${ }^{5}$ This results in a dataset with 662,016 observations for 6,574 companies. The number of firms included in the analysis increases over time. The number of U.S. companies with a fiscal year ending in December and an earnings' forecast by at least one U.S. analyst increased from 1,446 in 1990 to 2,569 in 2004. The analyses by industry use the industry classification, which is not available for 104,840 obser-

\footnotetext{
4 When looking at data by year, having the same end date means that the same events are occurring at the same horizon for all firms. Firms with fiscal years ending in December represent about 74 percent of all firms in the I/B/E/S database.

5 The results in Tables 2 through 4 were computed with the tails of the distribution of the data included. The results are broadly similar.
}

vations. As a result, the analyses by industry use 557,176 observations instead of the whole sample of 662,016 observations.

\section{Distribution of Forecast Errors}

Figure 1 shows the distributions of earnings and forecasted earnings. The graphs show the distribution of actual earnings and the distribution of forecasts by analysts made 1 month, 6 months, and 12 months before the earnings announcement. For example, the first graph (Figure 1A) shows actual earnings per share relative to the stock price and forecasts made 1 month before the announcement of earnings. The second graph (Figure 1B) shows the distribution of earnings and the distribution of the forecasts made 6 months before the earnings announcement, and the third graph (Figure 1C) shows the distribution of earnings and the distribution of the forecasts made 12 months before the earnings announcement. ${ }^{6}$ Deleting the top and bottom 1 percent of the distribution still leaves quite long tails to the distribution of earnings and, to a lesser but still easily discernible extent, the forecasts. To avoid obscuring detail, we also truncate these figures at $-\$ 0.50$ and $+\$ 0.50$ per dollar of share price. Table 1 shows the distribution of earnings, forecasts, and the forecast errors without the truncation. Relative to the total number of observations, the truncation excludes a small number of observations, mostly in the negative tail of the distributions.

The forecasts and actual earnings are strikingly similar, which is consistent with the forecasts being quite informative about actual earnings. The histograms for forecasts and actual earnings are distinguishable, but the overlap far outweighs the differences. The dashed vertical lines are drawn at the mean of actual earnings. The most common-modal—values of forecasted and actual earnings are similar. The solid curves in the figure represent normal distributions with the same

\footnotetext{
6 The distribution of earnings is not the same at each of the horizons. The figure shows the distribution of all forecasts and the distribution of the actual earnings that were predicted. Every firm with a forecast appears in the figure; every firm with no forecast does not appear in the figure. In addition, every firm with more than one forecast appears in the figure the same number of times as the number of its forecasts.
} 
Figure 1

\section{Actual Earnings and Earnings Forecast}

\section{A. 1-Month Forecast Horizon}

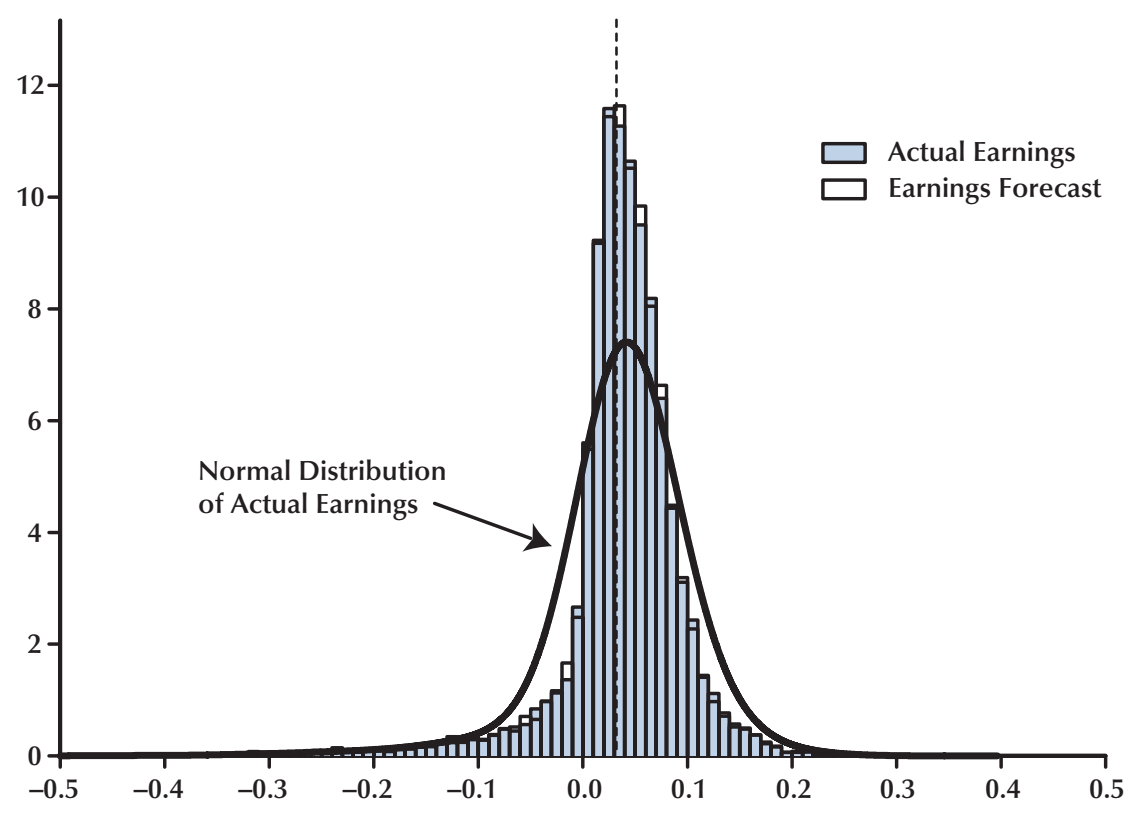

\section{B. 6-Month Forecast Horizon}

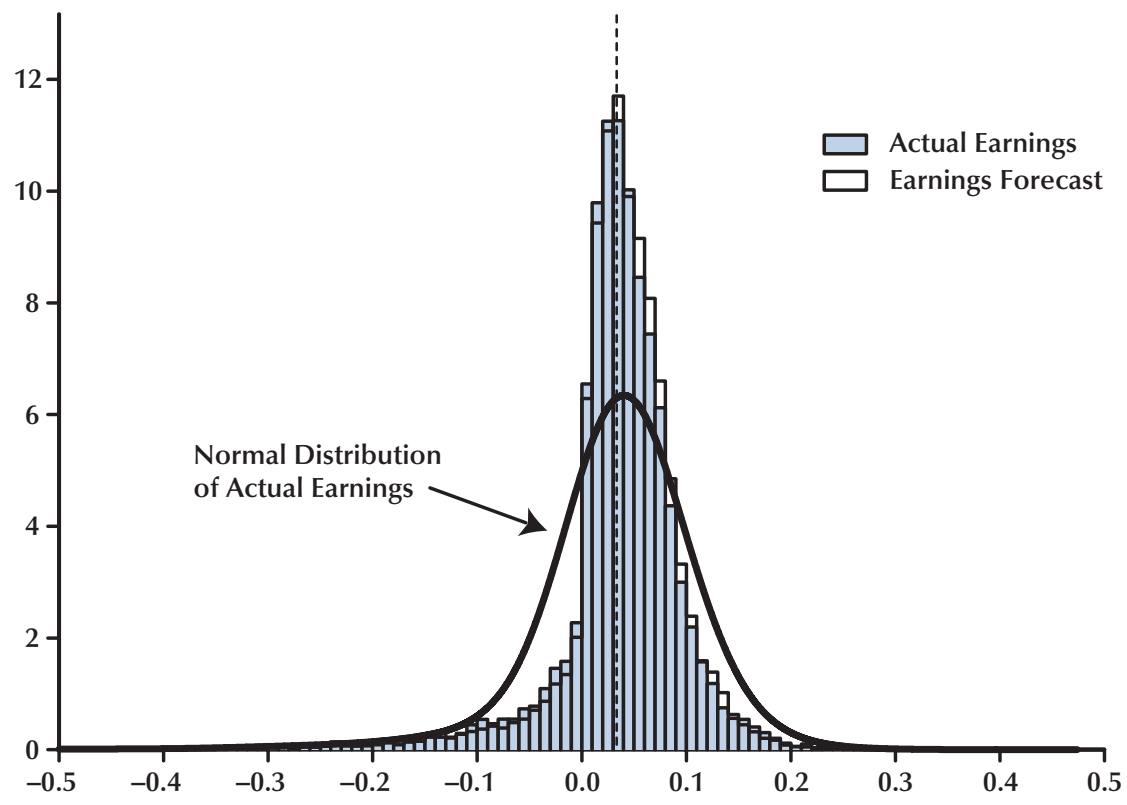




\section{Figure 1, cont'd}

\section{Actual Earnings and Earnings Forecast}

\section{12-Month Forecast Horizon}

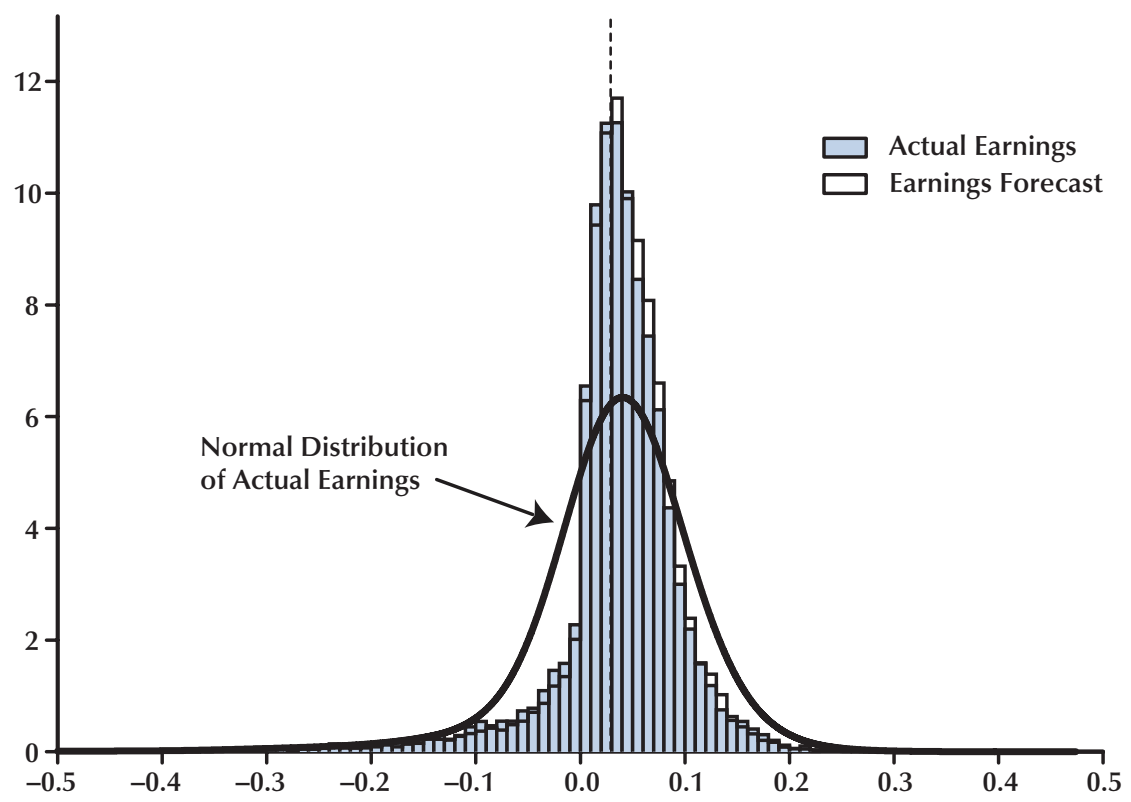

\section{Table 1}

Summary of Minimum and Maximum Values and Observations Suppressed in Figures 1 and 2

\begin{tabular}{|c|c|c|c|c|c|c|c|c|c|}
\hline \multirow[b]{2}{*}{ Variable } & \multicolumn{3}{|c|}{ 12-Month horizon } & \multicolumn{3}{|c|}{ 6-Month horizon } & \multicolumn{3}{|c|}{ 1-Month horizon } \\
\hline & Minimum & Maximum & $\begin{array}{c}\text { Number of } \\
\text { suppressed } \\
\text { observations }\end{array}$ & Minimum & Maximum & $\begin{array}{l}\text { Number of } \\
\text { suppressed } \\
\text { observations }\end{array}$ & Minimum & Maximum & $\begin{array}{c}\text { Number of } \\
\text { suppressed } \\
\text { observations }\end{array}$ \\
\hline Actual earnings & -1.6137 & 0.2844 & 150 & -1.1820 & 0.3350 & 58 & -0.9026 & 0.2844 & 11 \\
\hline Earnings forecasts & -1.1532 & 0.2933 & 76 & -0.7732 & 0.3267 & 21 & -0.6487 & 0.2778 & 10 \\
\hline Forecast errors & -1.2442 & 0.7614 & 89 & -1.1561 & 0.5533 & 15 & -0.6085 & 0.3531 & 2 \\
\hline
\end{tabular}

NOTE: For actual earnings and earnings forecasts there are no positive observations outside the -0.5 to +0.5 range. For forecast errors, there are 6, 2, and 0 excluded positive observations at the 12-, 6-, and 1-month forecast horizons, respectively; the remainder are negative observations. 


\section{Ciciretti, Dwyer, Hasan}

Figure 2

Forecast Errors

A. 1-Month Forecast Horizon

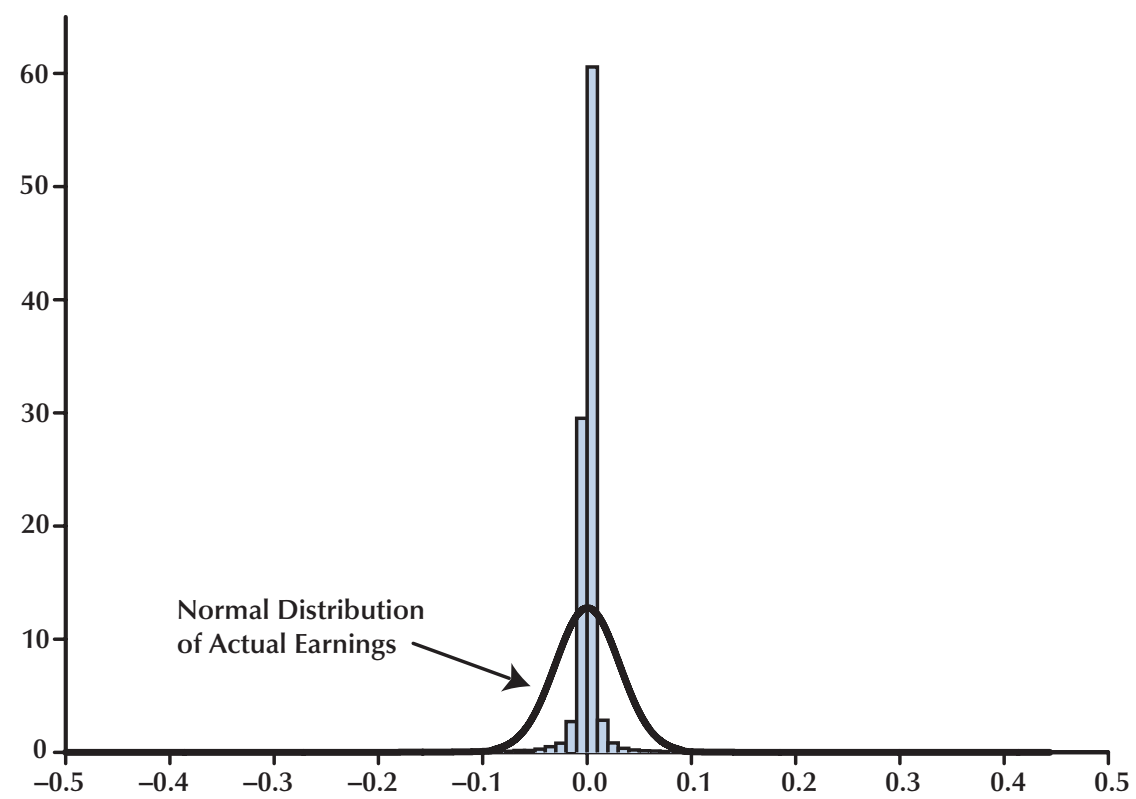

\section{B. 6-Month Forecast Horizon}

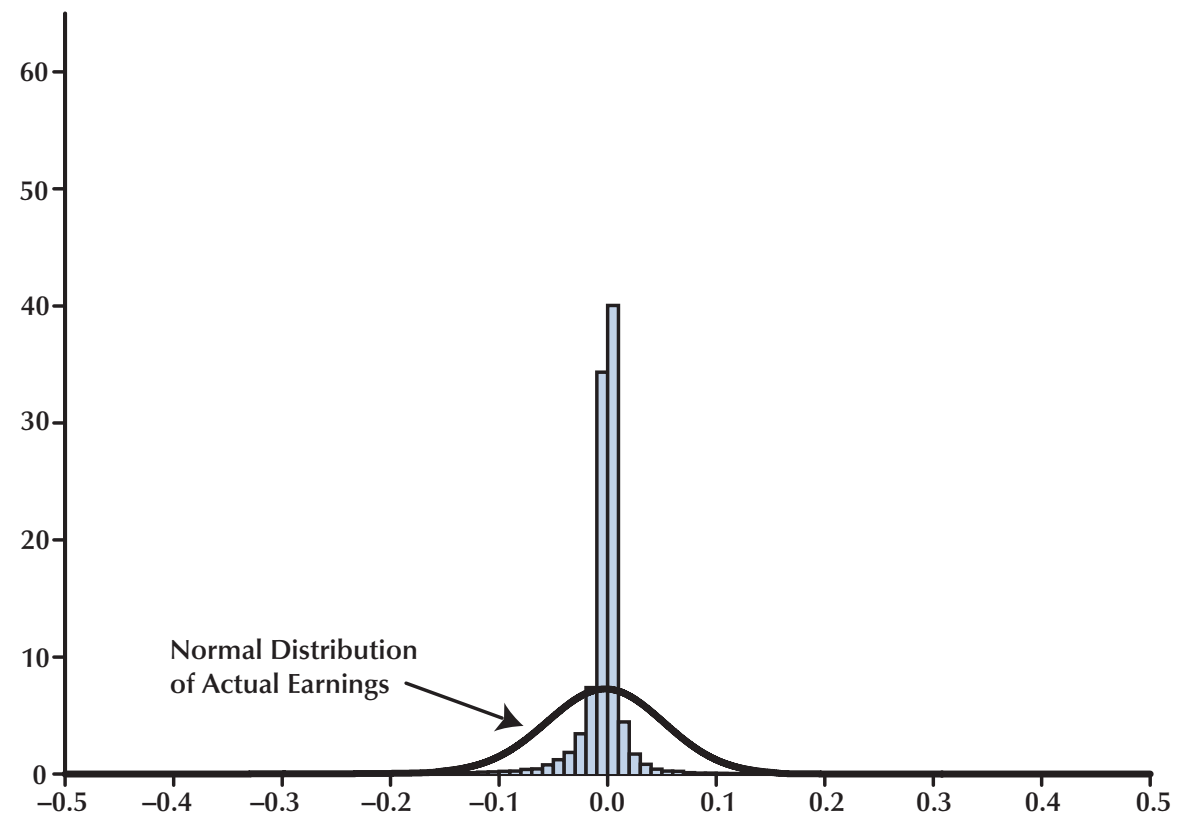




\section{Figure 2, cont'd}

\section{Forecast Errors}

\section{12-Month Forecast Horizon}

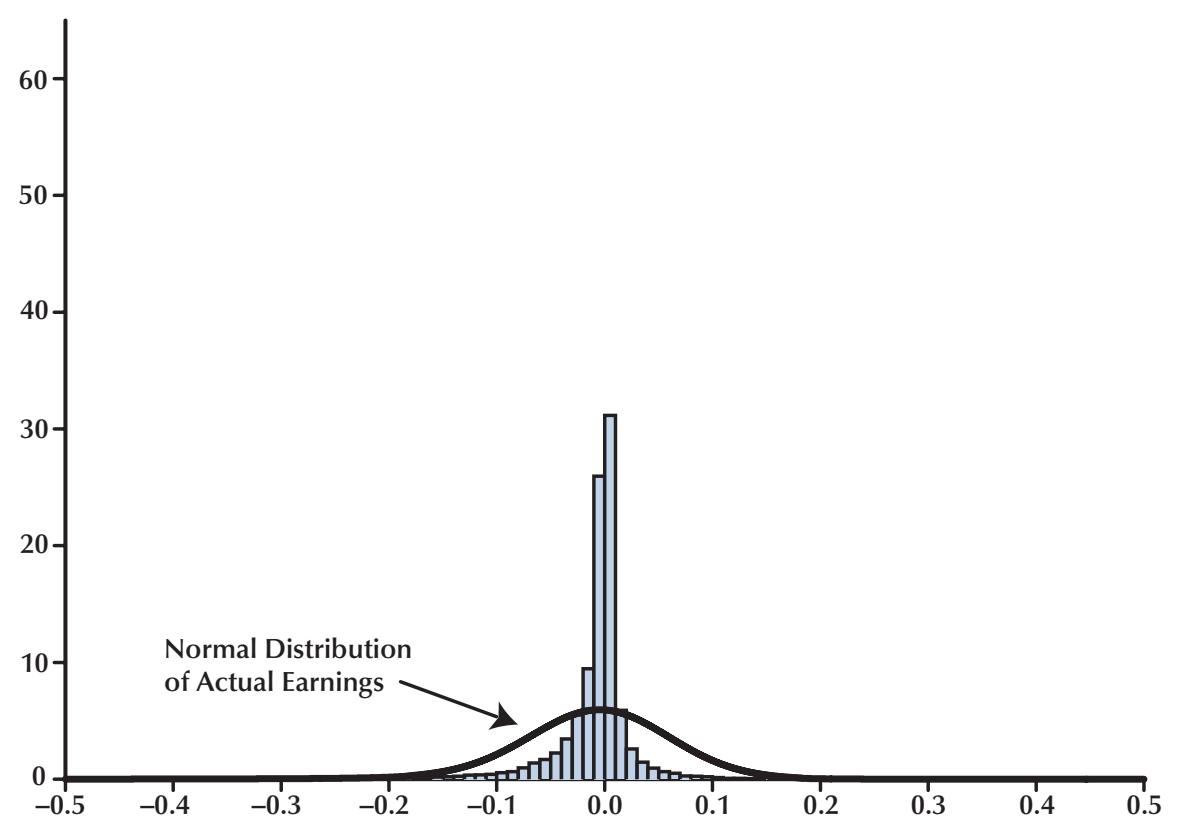

means and standard deviations as actual earnings. Actual and forecasted earnings have higher peaks at the mean value than the normal distribution and also have fatter tails. Because the total area must add up to 100 percent, this implies that the distributions of actual and forecasted earnings have fewer observations between the tails and the center of the distribution.

The graph of the 12-month-ahead forecasts shows the bias in longer-term forecasts. Although the distributions of actual and predicted earnings are quite similar, the histogram shows the tendency of more forecasts of above-average earnings and fewer forecasts of below-average earnings than actual earnings. The distribution of the 6month-ahead forecasts shows less bias. The distribution of the 1-month-ahead forecasts is more similar to the actual earnings.

The literature focuses on the deviations between the earnings and the forecasts, which makes it easy to lose sight of how informative the forecasts are about actual earnings. Analysts' earnings forecasts are quite informative about actual earnings.

Figure 2 shows the distributions of the forecast errors. A "positive forecast error" means that actual earnings exceed the forecasted earnings. A "negative forecast error" means that actual earnings fall short of the forecasted earnings. If all analysts forecasted earnings within a penny of earnings per dollar of share price, all the forecast errors would be within the two bars surrounding zero. Recall that the share price is the price before the start of the fiscal year, so this indicates that the analysts are coming very close to forecasting actual earnings. In fact, the forecast errors are quite peaked near zero, whether 12 months, 6 months, or 1 month before the announcement of actual earnings.

The earnings forecasts are closer to actual earnings 1 month before the earnings announcement than 12 months before the earnings announcement. 


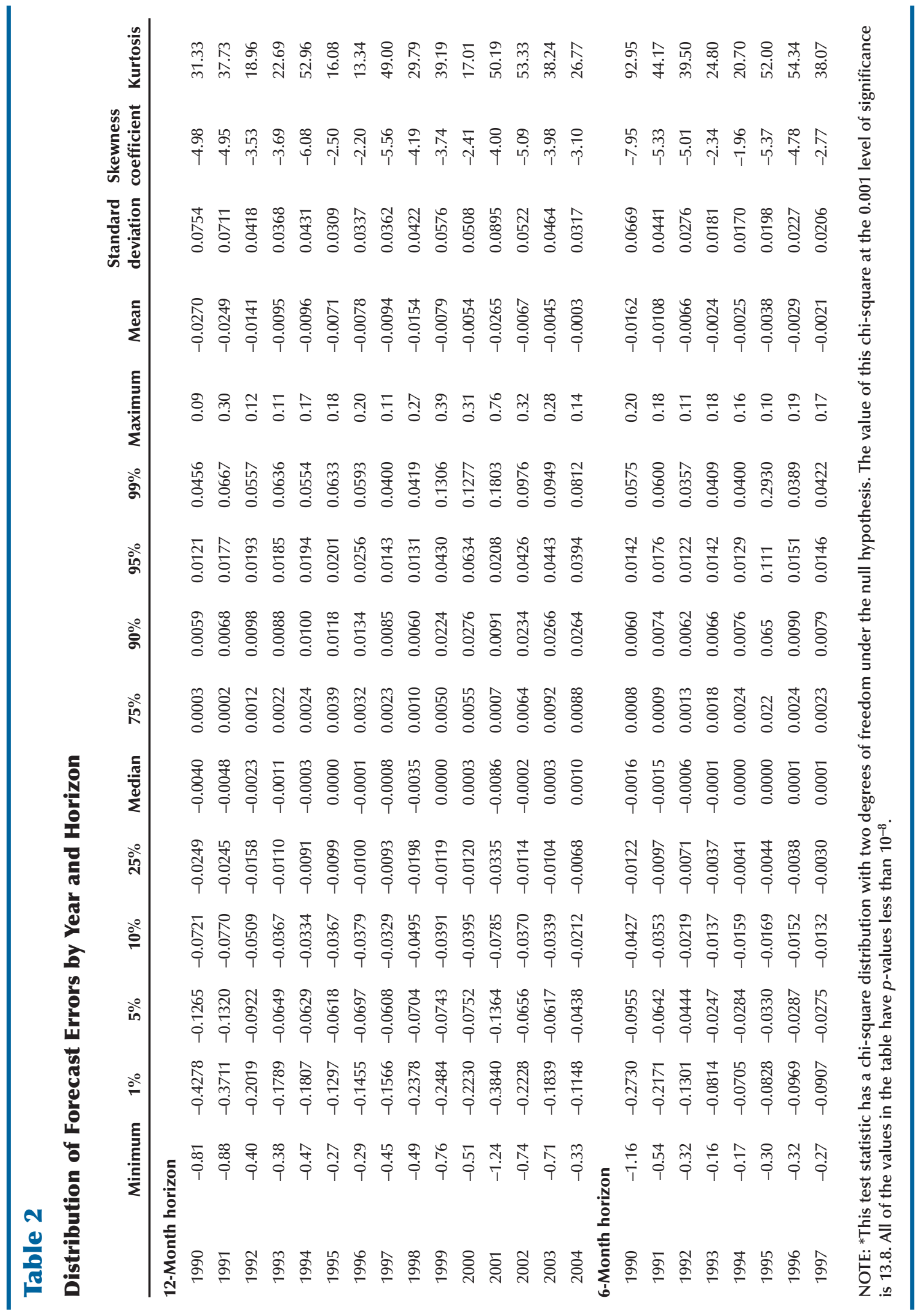




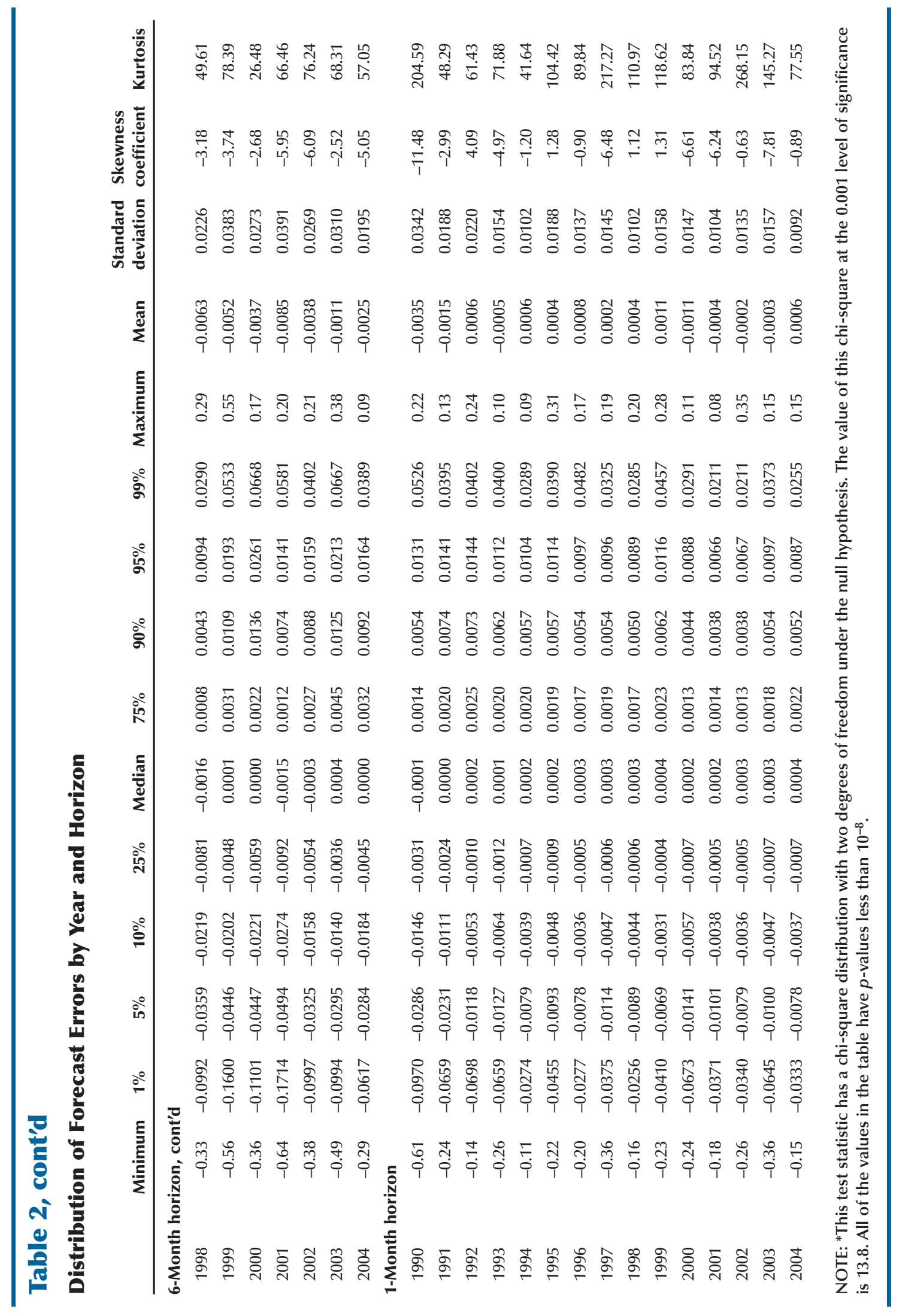




\section{Ciciretti, Dwyer, Hasan}

This convergence is expected if the forecasts are informed predictions. More information becomes available as time goes on, and this information is substantial: Eleven-twelfths of the year is past when the 1-month-ahead forecast is made. Firms announce earnings quarterly; when the 1-monthahead forecast is made, earnings for the first three quarters of the year have been announced and are known. Besides this relatively mechanical effect as time passes, other information becomes known about earnings as time passes and the magnitudes of forecast errors can be expected to decrease.

Over 90 percent of the forecasts made 1 month before the earnings announcement are within one penny of earnings per dollar of share price. There is a clear asymmetry in the distribution of these close forecast errors: 60 percent of the earnings are more than the forecasts and within a penny; 30 percent of the earnings are less than the forecasts and within a penny. The larger number of positive forecast errors can reflect analysts' forecasts that the analyst knows are too low; it also can occur for other reasons. For example, firms with actual earnings less than forecasted earnings may provide analysts with information before the announcement and forecasts are revised accordingly. The forecast errors 12 months ahead and 6 months ahead also show asymmetry, with many forecasts within a penny of actual earnings but more above zero than below.

Table 2 shows detailed information about the distributions of forecast errors by year at 12-month, 6-month, and 1-month horizons. The table shows the maximum and minimum values, the mean, standard deviation, measures of the skewness, and kurtosis of the distribution of forecast errors and selected percentiles of the distributions.

As Figure 2 suggests, the forecasts a month before the earnings announcement are much closer to actual earnings than are forecasts a year in advance. The standard deviation of forecast errors is a measure of the size of analysts' errors, independent of whether the forecast is above or below actual earnings. The standard deviation is substantially larger 12 months before earnings are announced than 1 month before the earnings announcement. For example, in 1990, the standard deviation is 0.0754 at a horizon of 12 months,
0.0669 at a horizon of 6 months, and 0.0342 at a horizon of 1 month. In 2004, the standard deviation is 0.0317 at a horizon of 12 months, 0.0195 at a horizon of 6 months, and 0.0092 at a horizon of 1 month.

The mean forecast errors in the table also decline as the announcement of earnings for the year approaches. The largest magnitudes of mean forecast errors in the table are for the 12-month horizon, -2.7 cents per dollar of share price in 1990 and 2001 and -2.5 cents per dollar of share price in 1991. The smallest magnitudes of mean forecast errors are for the 1-month horizon; the mean forecast error farthest from zero is -0.35 cents per dollar of share price in 1990. The mean forecast error has been hundredths of a penny per dollar of share price in most of the years since.

A large segment of the literature examines these mean forecast errors. The negative mean forecast errors are statistically significant and not trivial in magnitude at the 12-month horizon. Twelve months before earnings are announced, analysts' forecasts on average are overestimates of actual earnings. This overestimation is predictable, in an interesting and specific sense. If only the earnings forecasts are known a year in advance, it is predictable that actual earnings will be less on average. The difference is not large, but it is not zero and it is predictable. If analysts are attempting to forecast earnings well on average, their performance is not as good as it could be. In standard parlance, the forecasts are biased: The average forecast error is not zero.

Besides the arithmetic average, the median is another measure of the typical forecast. The median is the middle forecast, the forecast that divides the forecasts into two parts, with half the observations above the median and half below the median. The median forecast error is noticeably closer to zero than the average forecast error. This indicates that the typical negative forecast error is larger in magnitude than the typical positive forecast error. In other words, as Figure 2 shows, the distribution of forecast errors is not symmetric. The percentiles of the distribution clearly show this asymmetry of forecast errors. The consistently negative values of skewness in Table 2 also indicate what Figure 2 shows: Nega- 
tive forecast errors are larger in magnitude than the positive errors. ${ }^{7}$ Consistent with the figures, the measure of skewness indicates that forecast errors are skewed toward negative values.

Kurtosis measures how concentrated a distribution is around the mean compared with the number of observations in the tails of the distribution. ${ }^{8}$ The positive values for kurtosis indicate that the tails of the distribution have more observations than would be suggested by a normal distribution. Tests for normality of the distribution of forecast errors uniformly are inconsistent with a normal distribution. ${ }^{9}$

Figures 3 and 4 show aspects of the distributions of forecast errors for all horizons from 1990 to 2004. Figure 3 shows the mean and median forecast errors as the horizon-the length of time before the earnings announcement-approaches zero. It also shows the median in combination with the 25th and 75th percentiles of the distribution of forecast errors. The mean forecast errors are more strongly negative than the medians at long horizons and consequently show more convergence to zero. The median forecast errors are negative, with the largest magnitudes in 1990, 1991, 1998, and 2001 (see Figure 4). With the exception of 1998, these larger-magnitude median forecast errors are associated with recessions. ${ }^{10}$ The mean forecast errors are more strongly negative than the median forecast errors but decrease to quite close to zero by 1 month before the earnings announcement.

Figure 4 shows the distribution of forecast errors by year by graphing the median forecast error and the 25th and 75th percentiles of the

\footnotetext{
7 The measure of skewness is the third moment about the mean divided by the standard deviation cubed.

8 The measure of kurtosis is the fourth moment about the mean minus 3 , all relative to the fourth power of the standard deviation.

9 The test for normality is the Bera-Jarque test (1980). The inconsistency with a normal distribution matches up with the figures and tables; a normal distribution is symmetric and does not have the relatively fat tails indicated by the kurtosis statistics. The BeraJarque test statistics are not included in the table because the $p$-values uniformly are inconsistent with a normal distribution with $p$-values of $10^{-8}$ or below.

${ }^{10}$ The National Bureau of Economic Research dates the recession in 1990 and 1991 from July 1990 to March 1991 and the recession in 2001 from March 2001 to November 2001.
}

distribution for each horizon for each year from 1990 to 2004. The asymmetry of the distributions is quite apparent. It also is clear that actual earnings fall short of the longer horizon forecasts during recessions; this is indicated by the much more negative forecast errors during the recession years 1990, 1991, and 2001. Given the unpredictability of recessions, this is not especially surprising. The figure suggests that the distribution has become more symmetric over time, although the occurrence of recessions clearly is associated with greater asymmetry.

Table 3 presents the results of tests to determine whether the apparent skewness in the figures is statistically significant and consistent across horizons and years. ${ }^{11}$ The results of two tests are presented. The first is the sign test, which determines whether the median equals the mean. If a series' median exceeds its mean, the value of the statistic is positive. The $p$-value indicates the probability of that difference or a larger one if there really were no difference between the median and the mean. The second test determines whether the skewness coefficient is zero. If the skewness coefficient is zero and moments of the distribution up to the sixth are finite, then the skewness coefficient has an asymptotic normal distribution that can be used to construct a test. ${ }^{12}$

The sign tests indicate an asymmetry in forecast errors that persists from 1990 through 2004. Tests for the equality of the median and mean at all horizons are quite inconsistent with the equality of the two statistics. At the 12-month horizon, the median forecast error is closer to zero than the mean for all years from 1990 through 2004; all of the differences are statistically significant at any usual significance level. There is some suggestion that the difference between the mean and the median has been declining over time. The difference is far smaller in 2004 than in earlier years but the difference still is statistically

\footnotetext{
${ }^{11}$ The observations are repeated measures of forecasts by the same analysts for the same industries. As Keane and Runkle (1998) argue, this can introduce dependence in the data, which results in overstating the statistical significance of test statistics.

12 The mean of the asymptotic distribution of the skewness coefficient is zero under the null hypothesis and the variance is from Gupta (1967, pp. 850-51.)
} 


\section{Ciciretti, Dwyer, Hasan}

Figure 3

Forecast Errors by Horizon
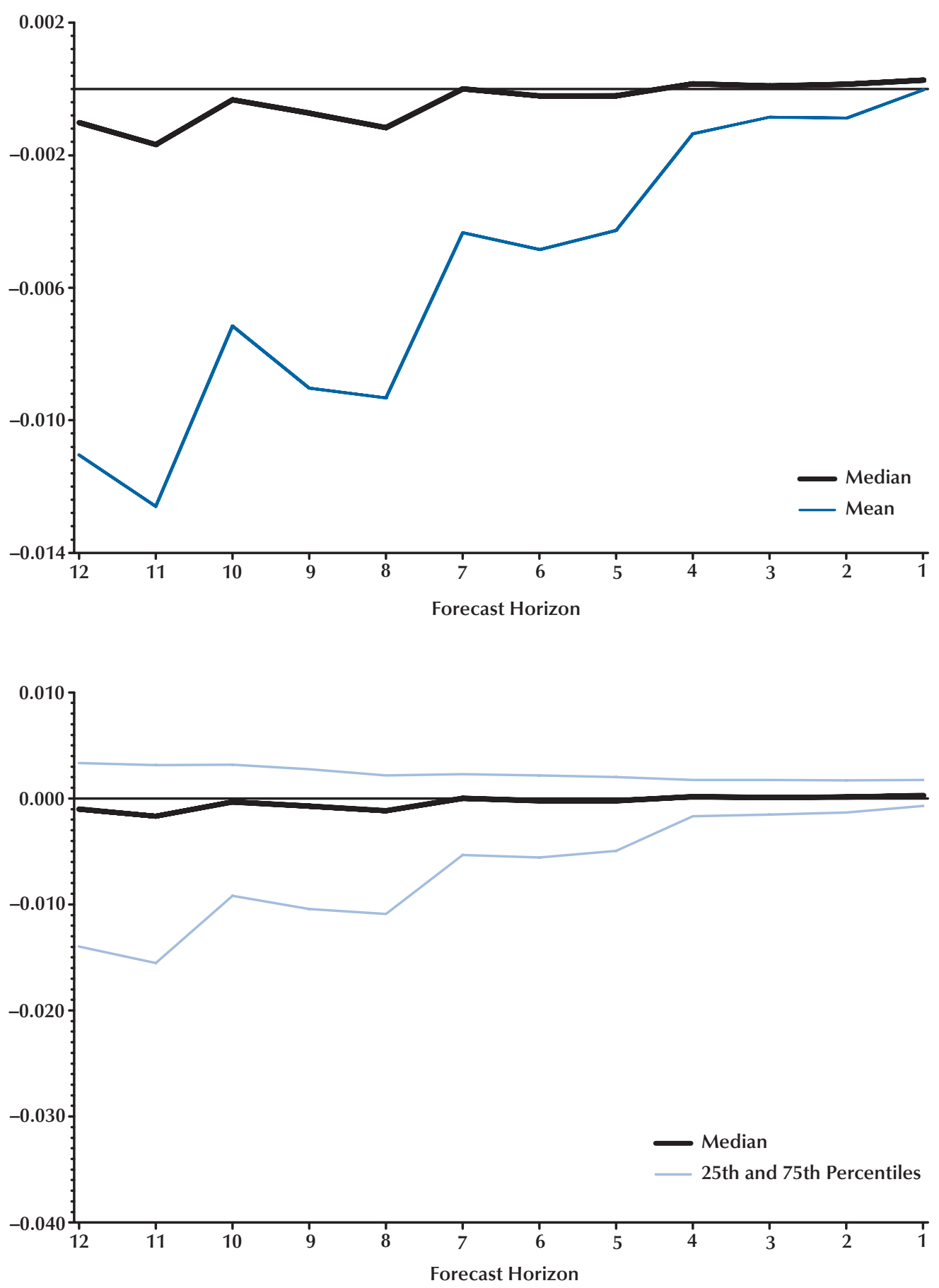


\section{Figure 4}

\section{Distribution of Forecast Errors by Year and Horizon}

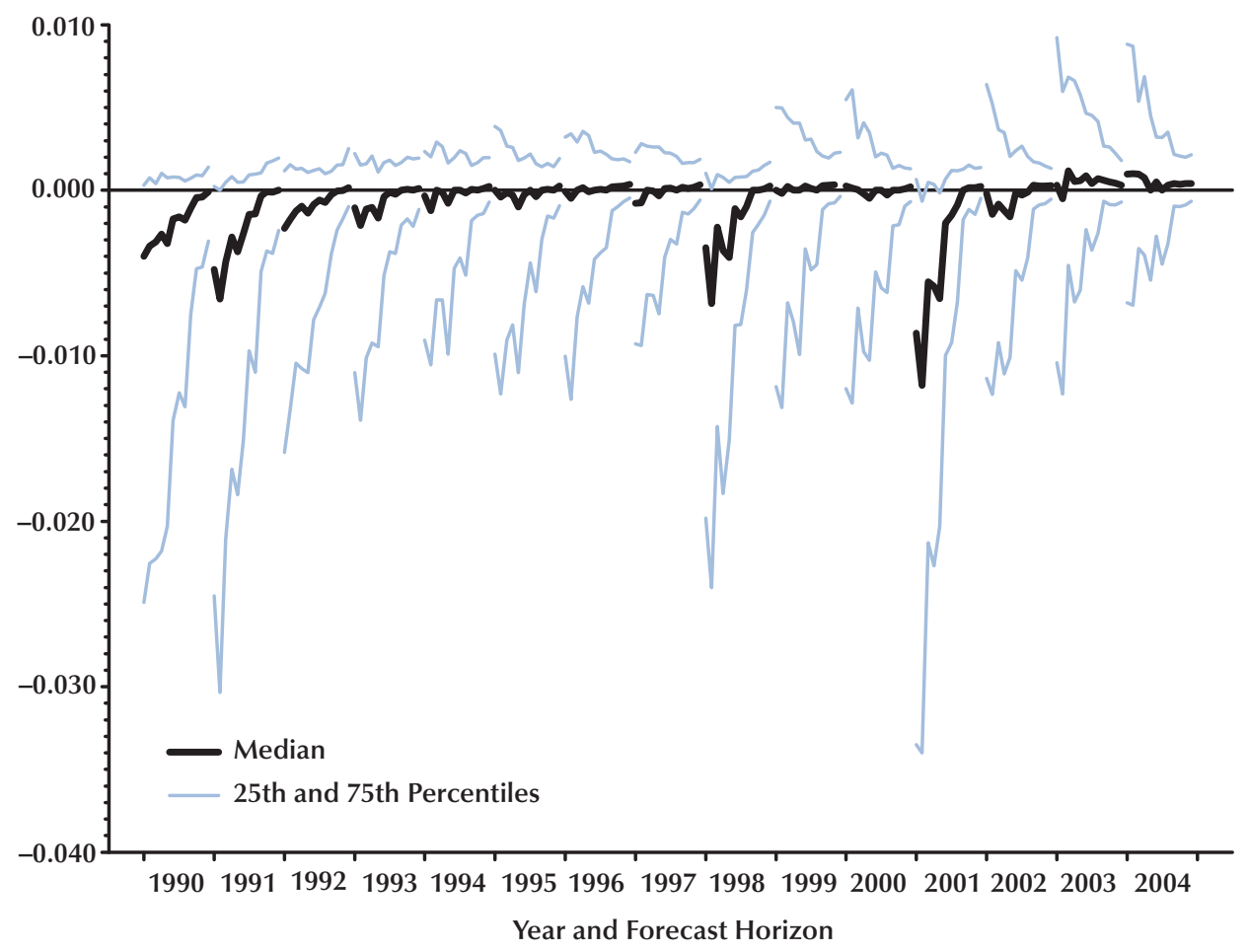

significant. The difference is one-tenth of a penny per dollar share price in 2004. Given a typical price-to-earnings ratio of 15 or 20, this implies a forecast error in earnings on the order of 2 cents per share per dollar of earnings 12 months ahead.

The tests using the skewness coefficient indicate that deviations from symmetry are persistent from 1990 through 2004 only at the 12-month horizon. The null hypothesis of symmetry for the 12-month horizon cannot be rejected in 2002 at the 5 percent significance level, a result most simply interpreted as due to chance rather than anything special about 2002. There is less evidence of overall skewness in any year at the 6month horizon and scant evidence of asymmetry at the 1-month horizon. This is an interesting contrast to the results using the median and mean. While there are statistically significant differences between the mean and median, the overall skewness of the distribution is less pronounced based on the third moment, which summarizes the asymmetry of the distribution. ${ }^{13}$

\section{Forecasts Errors Across Industries}

Forecast errors across firms and analysts are likely to differ for a variety of reasons, one being the likelihood that earnings are more predictable for some industries than others.

Figure 5 shows forecast errors by two-digit Global Industry Classification System categories. Forecast errors vary substantially by industry. All figures have the same scale to facilitate comparison of forecast errors across industries. Earnings in health care are predicted with relatively

${ }^{13}$ Too many rejections of the null hypothesis are possible if data have high kurtosis (Premaratne and Bera, 2005), as ours do. This is an issue only at the 12-month horizon because only that horizon shows rejections. Given the results for the median and mean and the levels of significance, we are inclined to take the rejections as being real rather than an artifact of kurtosis. 


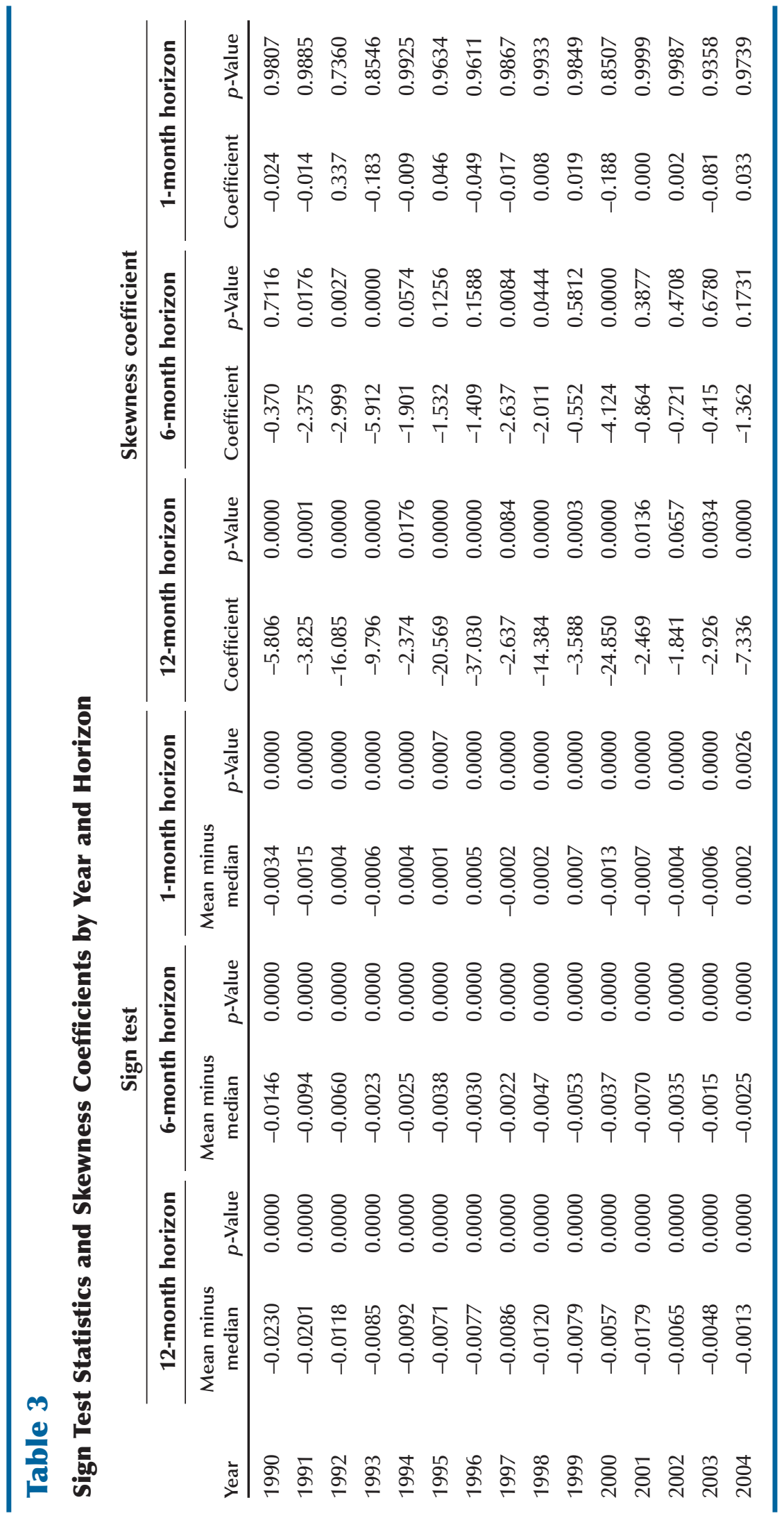


Ciciretti, Dwyer, Masan

Figure 5A

Distribution of Forecast Errors by Year, Horizon, and Industry

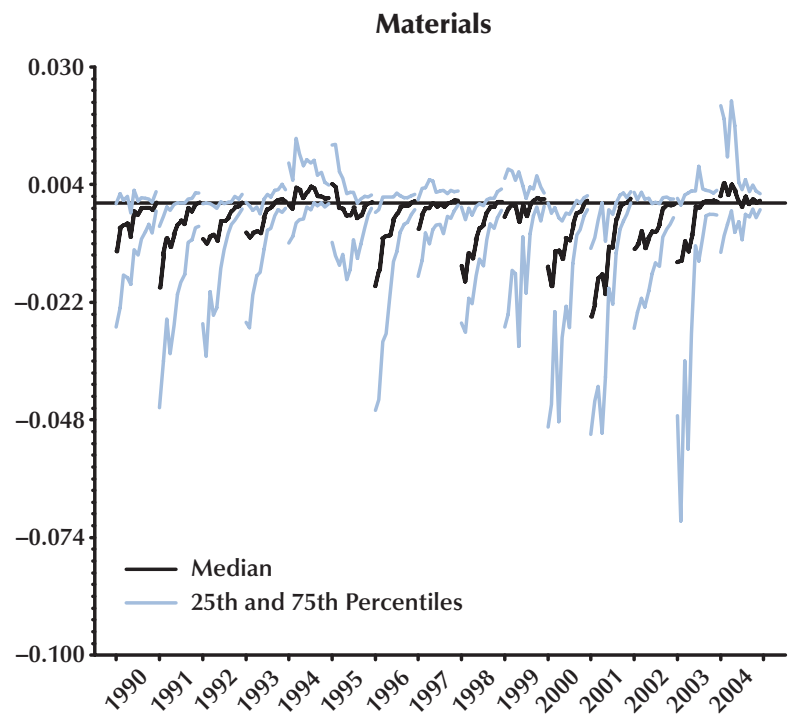

Year and Forecast Horizon

Consumer Discretionary

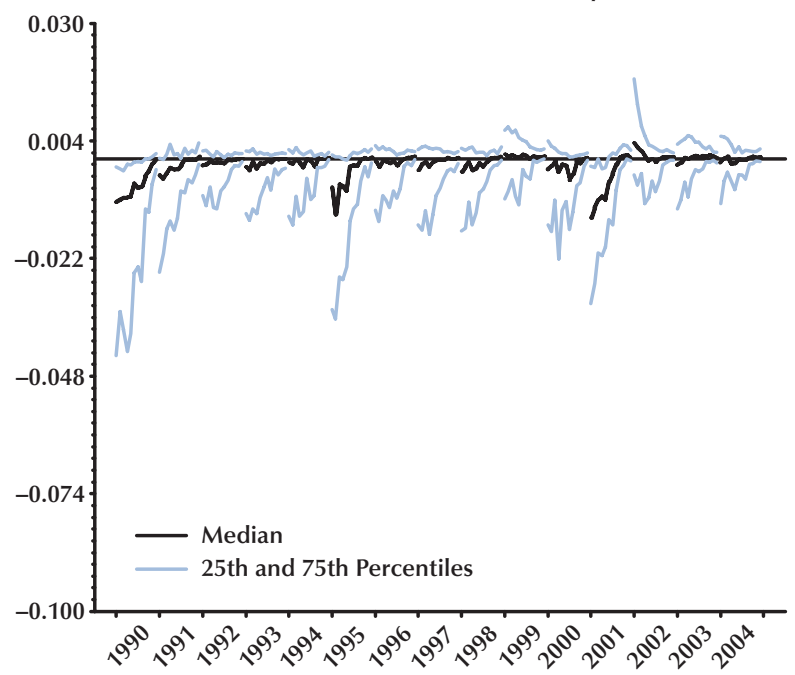

Year and Forecast Horizon

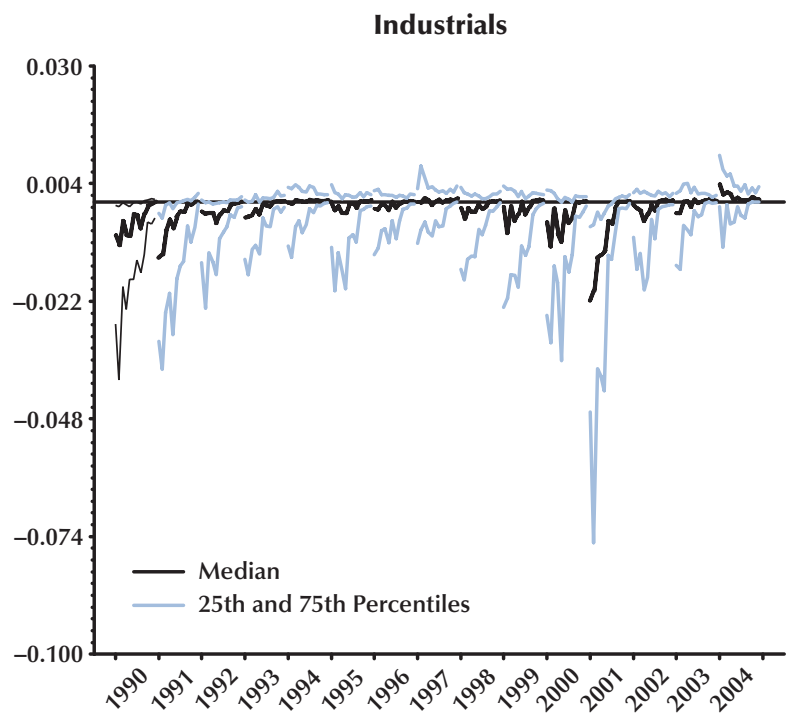

Year and Forecast Horizon

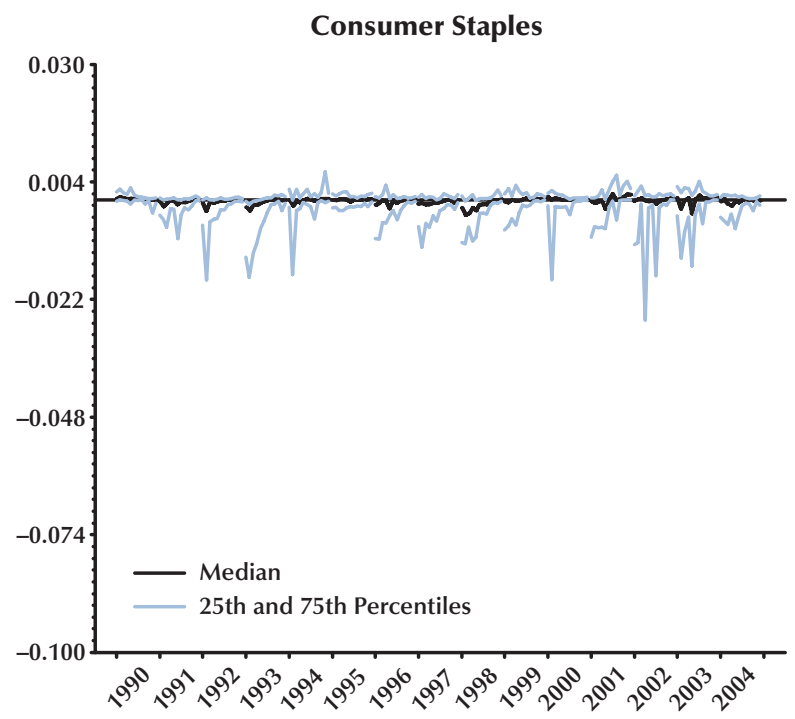

Year and Forecast Horizon

FEDERAL RESERVE BANK OF ST. LOUIS REVIEW

SEPTEMBER/OCTOBER, PART 22009

559 
Figure 5B

Distribution of Forecast Errors by Year, Horizon, and Industry
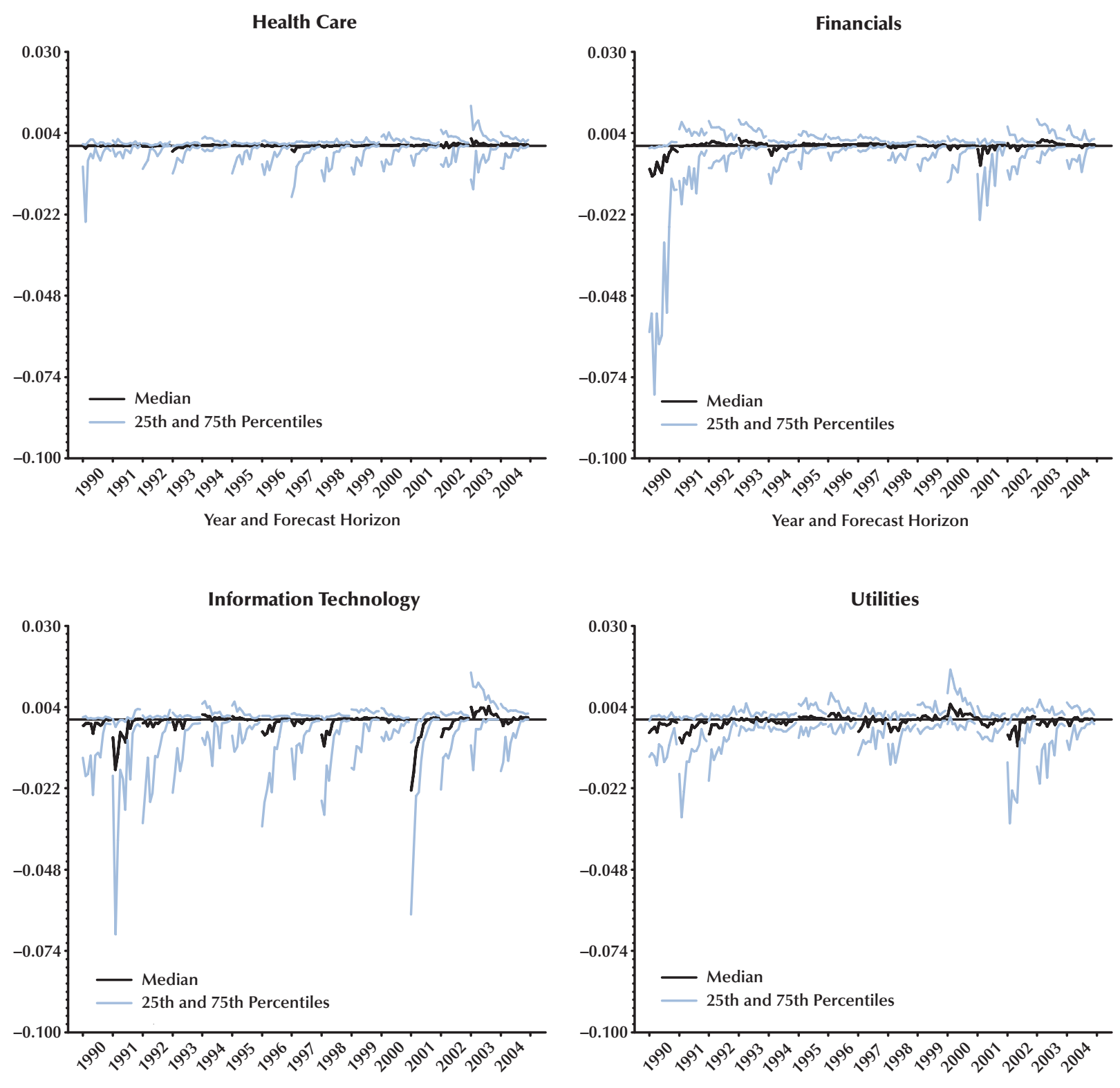

Year and Forecast Horizon

Year and Forecast Horizon 


\section{Figure 5C}

\section{Distribution of Forecast Errors by Year, Horizon, and Industry}
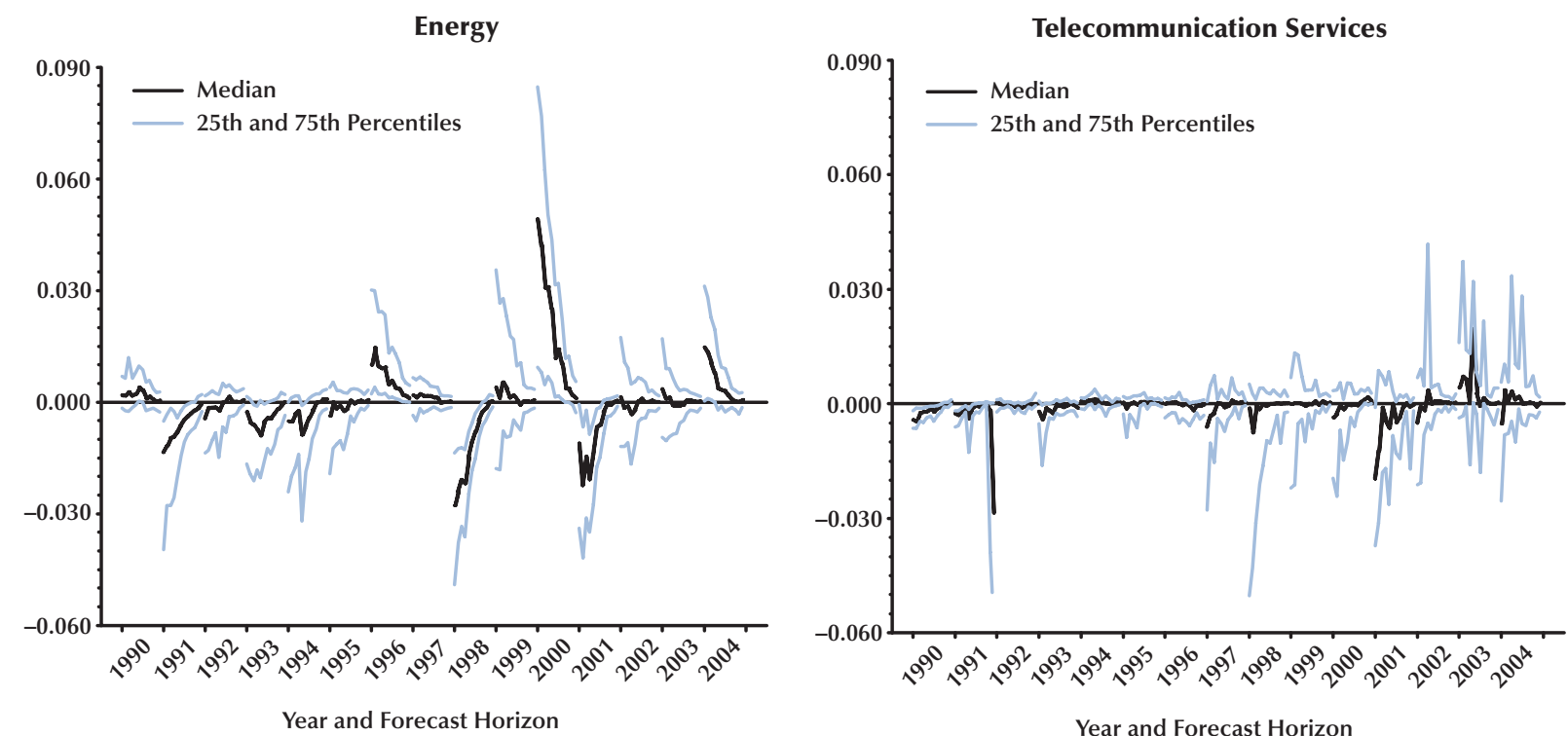

small forecast errors, and earnings in energy firms are predicted particularly poorly. It is plausible that earnings forecasts in less-volatile industries are smaller. Energy prices are subject to large unpredictable price swings, which obviously affect earnings. Although health care prices have risen substantially in recent years, the increases have been relatively persistent and therefore predictable. Health care is virtually unaffected by recessions, while the demand for energy falls in recessions. Some other industries show low earnings around recessions as well, such as materials and consumer discretionary goods. If recessions are not predicted, there is little reason to think that these earnings decreases are predictable either.

Sign tests not reported in the text are consistent with persistent differences between the median and means of the forecast errors across industries but suggest variation in the asymmetry by industry. The evidence is noticeably weaker for telecommunications and utilities.

\section{UNBIASEDNESS OF EARNINGS FORECASTS}

Almost all of the existing literature on analysts' forecasts examines whether their forecasts are biased and, generally speaking, finds that analysts overestimate earnings. This overestimation falls as the earnings announcement approaches, as indicated in Table 2, but future earnings typically are noticeably less than the average forecast. Some evidence and analysis suggests that analysts' forecasts change from overestimates to underestimates just before the earnings announcement. Such near-term forecasts are intended to be helpful to a firm's management because the announcement of higher-than-forecasted earnings generates favorable publicity and a higher stock price after the announcement. ${ }^{14}$

Asking for forecasts that are neither too high nor low on average seems like a relatively simple

${ }^{14}$ This is at least one reason to be dubious about this explanation if the near-term underestimation of earnings is persistent and predictable. Investors are likely to notice and discount the overestimation of earnings. 
request, especially compared with asking that forecasts be accurate. Even so, it is possible that analysts process the information available to them as best as possible, but some or all analysts do not have an incentive to produce forecasts that are correct on average.

\section{Analysts' Incentives and Forecasts}

At first glance, it seems obvious that unbiased forecasts are the best forecasts. A biased forecast is high or low on average. Such a bias suggests that the forecast can be improved by adjusting the forecast by the bias. There are many conditions in which an unbiased forecast is the best one. A common criterion for forecast errors is mean squared error. If a forecaster wants to minimize the expected mean squared error of a forecast, then an unbiased forecast is the best one. ${ }^{15}$ The expected squared forecast error applies an increasing penalty to forecasts farther from the average- $-\mathrm{a}$ forecast twice as far from zero is four times as bad.

The unbiased forecast-the mean-is not necessarily the best forecast in all circumstances. Suppose that someone is trying to forecast the value shown when a fair die is thrown. The mean forecast is the average of $1,2,3,4,5$, and 6 , which is 3.5. If the forecaster's earnings depend on how close the forecast is to the actual value, the best forecast in fact is 3.5. On the other hand, if the forecaster gets paid only when the value shown is the same as the value forecasted, this unbiased forecast guarantees that the forecaster always loses. The die will never have the value 3.5. If the forecaster is paid when the forecast is the same as the value thrown and values from 1 to 6 are equally likely, any integer forecast from 1 to 6 is equally good and 3.5 never is predicted. While this is a simple example, the point is more general. The value forecasted depends on the forecaster's incentives and the distribution of the data. An unbiased forecast may not be the "best" forecast.

There also are objectives similar to minimizing the expected squared error that lead to forecasts being "biased." If a forecaster wants to minimize the expected absolute deviation of the forecast

${ }^{15}$ A minimum expected squared error forecast minimizes the expected value of the squared forecast errors. error, then the median is the best forecast. ${ }^{16}$ The absolute forecast error applies an increasing penalty to forecast errors farther from zero-a forecast error twice as far from zero is twice as bad. The cost of forecast errors increases linearly with the size of the error. The forecast that minimizes the expected absolute forecast error is the median, not the mean (or more precisely, the arithmetic average). If the mean and the median are the same, this is a distinction that does not matter. On the other hand, if the distribution is not symmetric, as the earnings distribution is not, the median is a better forecast than the mean if a forecast error's cost increases linearly with the forecast error. ${ }^{17}$

Analysts do not make forecasts in isolation. Other analysts are making forecasts as well, and the existence of other forecasts can affect an analyst's forecasts in many ways. A simple, common forecasting game illustrates that an unbiased forecast may not be an analyst's best forecast. Consider a forecasting game in which the smallest forecast error wins and receives a prize; everyone else receives nothing. Analysts' situations may be closer to this game than to isolated forecasts. In this game, the incentive is to be the closest. If you are not the closest, then it matters not at all whether your forecast error is almost as good as the best or is far away. More generally, any analyst's forecast will depend on what he or she thinks other people will forecast or what others have already forecasted. A simple example is one in which two people guess someone else's pick of a number between 0 and 10 . The unbiased forecast is 5. Suppose that the first person picks 5 . If the second person picks 5 , then he or she cannot win, only tie. A pick of either 4 or 6 can increase the expected winnings of the second person if there is no payoff from tying. Neither 4 nor 6 is unbiased, but that doesn't matter. Either number maximizes expected winnings, and it is winnings that matter. This suggests that, even if analysts' forecasts are biased, it is important to consider analysts' incentives before denouncing them as "irrational" or "ignoring information readily available to them."

\footnotetext{
${ }^{16}$ A minimum expected absolute error forecast minimizes the expected absolute value of the forecast errors.

${ }^{17} \mathrm{Gu}$ and $\mathrm{Wu}(2003)$ discuss this in more detail.
} 
Among others, Hong and Kubik (2003), Clarke and Subramanian (2006), Ottaviani and Sørensen (2006), and Ljungqvist et al. (2007) highlight factors that can explain a nonzero predictable forecast error. For example, Clarke and Subramanian (2006) suggest that an analyst who performs poorly and is at risk of being fired is more likely to make a "bold" forecast that is unlikely to be correct but will save the analyst's job if it is correct.

\section{Tests for Unbiasedness}

The proposition that analysts' forecasts are biased is simple to determine with a test of whether the average difference between actual earnings and forecasted earnings is zero. ${ }^{18}$ Given the evidence above that forecast errors are not symmetric, it is worthwhile to test whether the median forecast error is zero, in addition to testing whether the mean forecast error is zero. A simple $t$-test is used for the latter purpose. The test that analysts' median forecast errors are zero is the sign test for deviations from zero.

Table 4 presents the mean and median forecast errors by industry at the various horizons and $p$-values for tests of whether the mean and median forecast errors are zero. The mean forecast errors are far smaller at the 1-month horizon than at longer horizons. At the 12-month horizon, the mean forecast error indicates that forecasted earnings are greater than actual earnings by about 1 cent per dollar of share price. At the 1-month horizon, the mean forecast errors indicate that forecasted earnings are greater than actual earnings by about one-hundredth of a cent per dollar of stock price.

How big are these forecast errors? Mean earnings for all firms in our data are 2 cents per dollar of share price; median earnings are 3.9 cents per dollar of share price. A forecast error of 1 cent per dollar of share price at the 12-month horizon is large relative to average earnings of 2 cents. A forecast error of one-hundredth of a cent at the 1-month horizon is relatively small and not obviously economically insignificant.

The median forecast error for all industries is minus nine-hundredths of a cent per dollar of

\footnotetext{
${ }^{18}$ The test is a standard $t$-test of whether the mean forecast error equals zero using the asymptotic normal distribution.
}

share price at the 12-month horizon. At the 6month and 1-month horizons, the median forecast errors are minus two-hundredths of a cent per dollar of share price and three-hundredths of a dollar per dollar of share price. All these magnitudes based on the median are statistically significantly different from zero. Median forecast errors of hundredths of a cent per dollar of share price are not particularly large relative to median earnings of about 4 cents per dollar of share price.

The means and medians vary substantially by industry. The mean forecast errors by industry mirror the overall mean forecast errors, declining in magnitude as the horizon shortens. The median forecast errors show substantial variability across industries in terms of magnitude. At the 1-month horizon, all of the magnitudes are of the same small order as the overall median, with the largest being five-hundredths of a cent per dollar of share price.

Table 5 shows the results of tests to determine whether the average and median forecast errors are zero by year. With the exception of the last year in the table, 2004, all $p$-values for testing whether mean forecast errors are zero at the 12month horizon are less than $10^{-4}$. All mean forecast errors are negative, indicating that forecasts on average are greater than actual earnings. Mean forecasts 6 months ahead look much like the forecasts at the 12-month horizon. The forecasts at the 1-month horizon look quite a bit different. At the 1-month horizon, there is little evidence in our data of bias in the mean forecast: 8 of the 15 forecasts are positive and 7 are negative. Nine of the forecasts are statistically significant at the 5 percent level, but they are not uniformly positive or negative. There is little evidence to support a conclusion that mean forecasts at the 1-month horizon are uniformly above or below zero.

The median forecasts in Table 5 are closer to zero than the mean forecasts. The results of the statistical tests that the median forecasts equal zero indicate that they are not zero, but the magnitudes generally are hundredths of a cent per dollar of share price.

At the 12-month horizon, the overall median forecast error is negative, but this masks interesting variation by year. In five years-1995, 1999, 


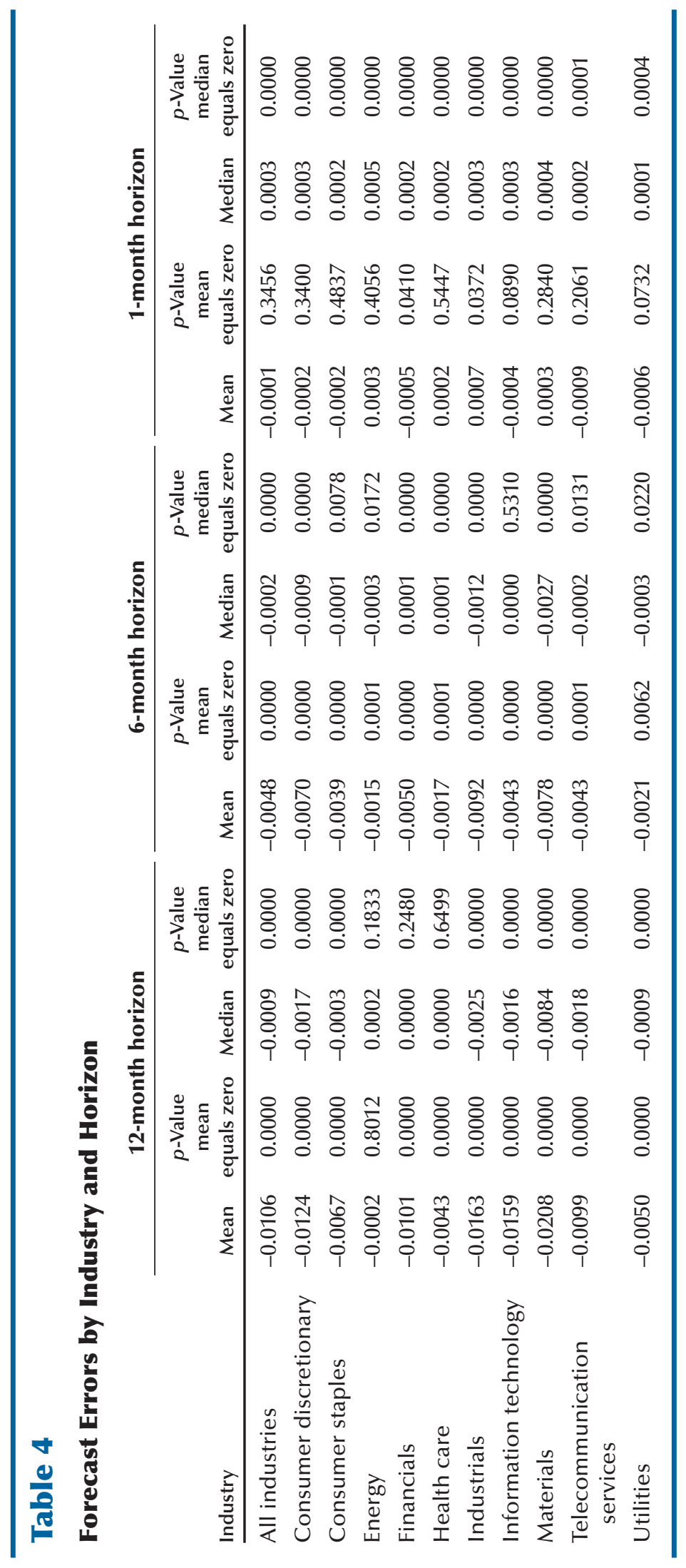




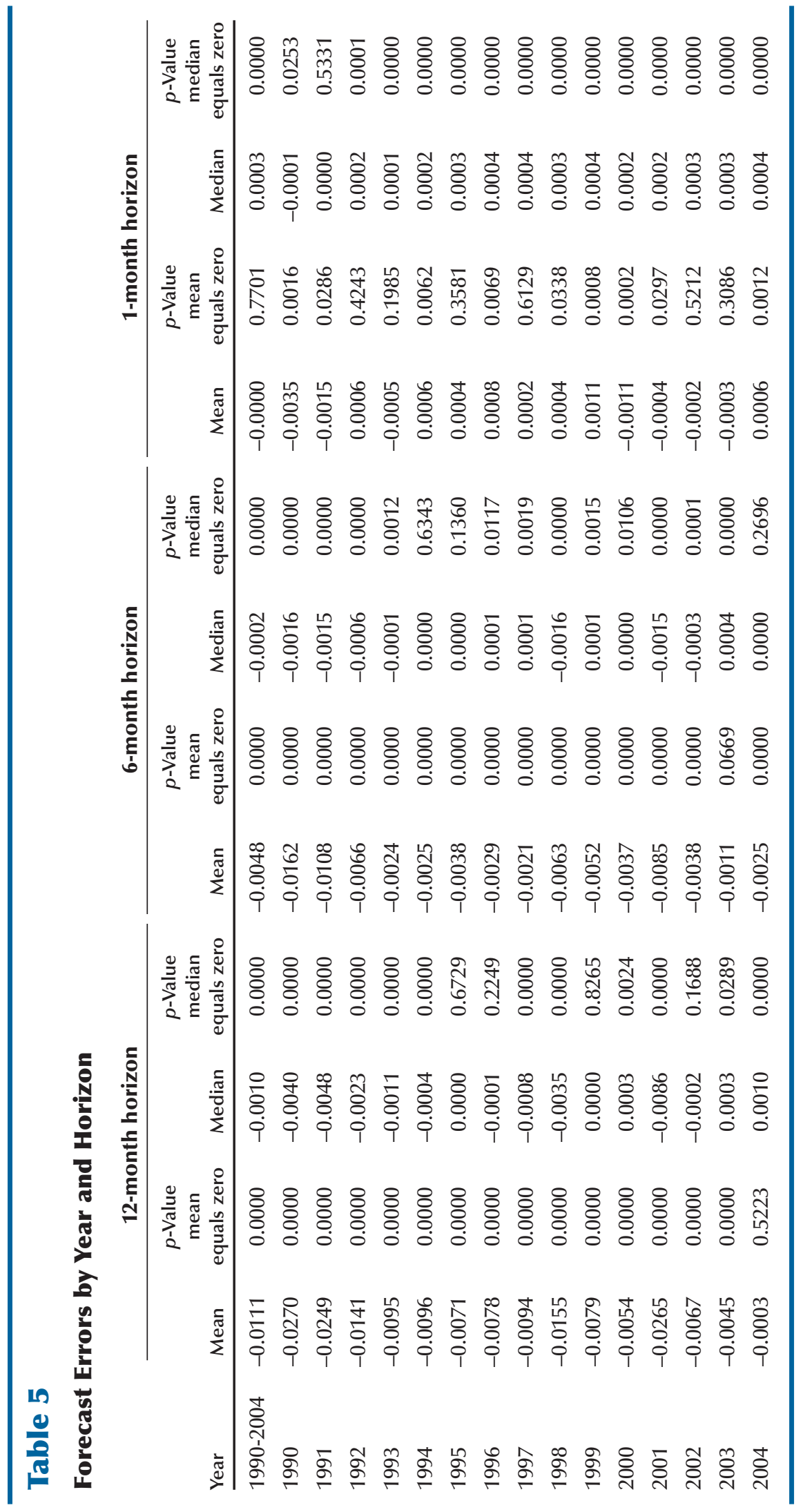




\section{Ciciretti, Dwyer, Hasan}

2000, 2003, and 2004-the median forecast error at the 12-month horizon is positive, indicating that the median forecast is an underestimate of earnings. This is the opposite of the bias in the mean forecast. It is interesting that these years are toward the end of the period. For four years1995, 1996, 1999, and 2002-the median forecast error is not statistically significantly different from zero at the 5 percent significance level. Two of these years have positive median forecast errors and two have negative ones. At this 12-month horizon, only 8 of the 15 years have median forecast errors that are negative and statistically significant. Moreover, of the medians at this 12-month horizon from 1999 to 2004, only the recession year 2001 has a negative median forecast error that is statistically significantly different than zero; 3 of the 5 years have positive median forecast errors that are statistically significant. These results are consistent with the median forecast errors not always being zero, but there is little support for the median forecasts uniformly being too high or too low.

At the 6-month horizon, median forecast errors also provide little support for typical overestimation of earnings throughout the period. The median forecast errors are negative in 8 of the 15 years, barely more than half the 15 years. The median forecast errors are positive and statistically significant at the 5 percent significance level in years 1996, 1997, 1999, 2000, and 2003.

At the 1-month horizon, the median forecast errors are positive in all years but 1990, a result consistent with the stylized view in the literature that forecast errors are underestimates close to the announcement. It is interesting that our data support such an inference using medians but provide much less support with means. All median forecast errors at the 1-month horizon are quite small, never larger in magnitude than fourhundredths of a cent per dollar of share price. Economically, this is not that far from zero.

\section{CONCLUSION}

Our data for U.S. analysts' forecasts of U.S. firms' earnings from 1990 through 2004 show typical results: Analysts' forecasts are greater than earnings on average a year before earnings are announced. Six months before the earnings announcements, mean earnings forecasts also are greater than actual earnings. On the other hand, median earnings forecasts are about as likely to be above actual earnings as below them at both the 12-month and 6-month horizons. A month before the announcement, mean forecast errors provide little support for predictable differences between average earnings and forecasts. Median forecast errors at the 1-month horizon, though, generally are positive and statistically significant, indicating that the analysts' median forecast is less than earnings on average. These median forecast errors are relatively small in magnitude, though —on the order of hundredths of pennies of earnings relative to the share price-when average and median earnings are about 2 and 4 cents, respectively, relative to the share price.

Mean forecast errors and median forecast errors differ substantially. The distribution of forecast errors is asymmetric, with mean forecast errors substantially larger in magnitude than median forecast errors at the 6-month and 12month horizons. The distribution of earnings is asymmetric. The distribution of earnings forecasts also is asymmetric but not sufficiently asymmetric that forecast errors are symmetric. There are substantial differences in mean and median forecast errors across industries. We also find substantial differences in mean and median forecast errors by year, with the largest forecast errors in recession years.

\section{REFERENCES}

Bera, Anil K. and Jarque, Carlos M. "Efficient Tests for Normality, Homoscedasticity and Serial Independence of Regression Residuals.” Economics Letters, October 1980, 6(3), pp. 255-59.

Clarke, Jonathan and Subramanian, Ajay. "Dynamic Forecasting Behavior by Analysts: Theory and Evidence." Journal of Financial Economics, April 2006, 80, pp. 81-113. 
$\mathrm{Gu}$, Zhaoang and Wu, Joanna S. "Earnings Skewness and Analyst Forecast Bias." Journal of Accounting and Economics, April 2003, 35(1), 5-29.

Gupta, M.K. "An Asymptotically Nonparametric Test of Symmetry." Annals of Mathematical Statistics, 1967, 38(1), pp. 849-66.

Hong, Harrison and Kubik, Jeffrey D. "Analyzing the Analysts: Career Concerns and Biased Earnings Forecasts." Journal of Finance, February 2003, 58, pp. 313-51.

Keane, Michael P. and Runkle, David E. "Testing the Rationality of Price Forecasts: New Evidence from Panel Data." American Economic Review, September 1990, 80(4), pp. 714-35.

Keane, Michael P. and Runkle, David E. "Are Financial Analysts' Forecasts of Corporate Profits Rational?” Journal of Political Economy, August 1998, 106(4), pp. 768-805.

Ljungqvist, Alexander; Marston, Felicia; Starks, Laura T.; Weid, Kelsey D. and Yan, Hong. "Conflicts of Interest in Sell-Side Research and the Moderating Role of Institutional Investors." Journal of Financial Economics, August 2007, 85(2), pp. 420-56.

Ottaviani, Marco and Sørensen, Peter N. "The Strategy of Professional Forecasting." Journal of Financial Economics, August 2006, 81(2), pp. 441-66.

Premaratne, Gamini and Bera, Anil. "A Test for Symmetry with Leptokurtic Financial Data." Journal of Financial Econometrics, Spring 2005, 23(2), pp. 169-87.

Sirri, Erik. "Investment Banks, Scope, and Unavoidable Conflicts of Interest." Federal Reserve Bank of Atlanta Economic Review, Fourth Quarter 2004, 89(4), pp. 23-35.

Smith, Randall; Scannell, Kara and Davies, Paul. “A 'Brazen' Insider Scheme Revealed.” Wall Street Journal, March 2, 2007, pp. C1, C2. 
